\title{
Effect of Zinc Supplementation on the Frequency and Consistency of Stool in Children with Acute Diarrhea
}

Ghulam Shabbir Laghari ${ }^{1}$, Zahid Hussain ${ }^{2}$, Huma Shahzad ${ }^{3}$

1. Pediatrics, Liaquat University of Medical and Health Sciences, Jamshoro, PAK 2. Pediatrics, National Institute of Child Health, Karachi, PAK 3. Internal Medicine, Dow University of Health Sciences, Karachi, PAK

Corresponding author: Zahid Hussain, zahidhussain91393@gmail.com

\section{Abstract \\ Introduction}

Acute diarrhea in young children is a prevalent and distressing pediatric illness. The role of zinc therapy in the improvement of stool consistency and the shortening of the duration of diarrhea is still controversial. The aim of this study is to assess the effect of oral zinc supplementation in acute diarrhea.

\section{Methods}

Children of age 28 days till five years presenting in the outpatient department with acute diarrhea were included. Oral zinc supplementation was included in the anti-diarrheal regime of half of the children $(\mathrm{n}=50)$; the other half $(\mathrm{n}=50)$ were not given zinc. Mean body weight and the frequency and consistency of stool were noted for both groups on Days 1 and 3.

\section{Results}

The zinc group showed a significantly reduced frequency of diarrheal episodes on the third day of intervention ( $p<.00001)$. More children in the zinc group had soft to firm stool consistency than in the nonzinc group $(\mathrm{p}=.01)$.

\section{Conclusion}

Oral zinc supplementation has a promising role in reducing the duration of diarrhea and improving stool consistency in children with acute diarrhea. Oral zinc supplementation should be made a mandatory part of the anti-diarrheal regime for Pakistani children.

Received 03/05/2019 Review began $03 / 07 / 2019$ Review ended 03/07/2019 Published 03/11/2019

○ Copyright 2019 Laghari et al. This is an open access article distributed under the terms of the Creative Commons Attribution License CC-BY 3.0., which permits unrestricted use, distribution, and reproduction in any medium, provided the original author and source are credited.
Categories: Internal Medicine, Pediatrics, Gastroenterology

Keywords: acute diarrhea, oral zinc supplementation, pakistan, pediatric diarrhea, zinc in diarrhea

\section{Introduction}

Despite the promising role of oral rehydration solution (ORS), acute diarrhea is one of the major preventable causes of childhood deaths. Globally, diarrhea is still the most common pediatric morbidity, with 1.5 billion episodes and almost two million deaths per year [1-2]. In middle-to-low income countries, the prevailing scenario is even worse. According to the Pakistan Demographic and Health Survey conducted in 2013, almost $23 \%$ of children age five years and under had suffered from diarrhea two weeks preceding the survey. The prevalence of diarrhea was highest among children aged six and eleven months (35\%); a span during which solid foods are first introduced into the child's diet [3].

The World Health Organization (WHO) has recommended zinc supplementation for 10 to 14 days along with low osmolarity oral rehydration solution (ORS) in acute diarrheal episode [4]. The role of oral zinc supplementation in acute pediatric diarrhea has been related to its ability to modify the host's resistance mechanism toward the infectious agents, thereby, reducing the risk, frequency, and duration of diarrhea. Zinc also plays a critical role in modulating the cell membrane and cellular function, thereby, improving immunity [5]. A study conducted by Trivedia et al., in 2013, showed a $62 \%$ reduction in stool frequency per day in the zinc group as compared to only $26 \%$ in the placebo-supplemented group [6]. In a systemic review published in 2010, it was concluded that oral zinc supplementation shortens the mean duration of acute diarrhea by up to $20 \%$ and persistent diarrhea by up to $30 \%$ [7].

Despite the fact that Pakistan is among the first countries to include zinc in its pediatric diarrhea treatment protocol, only $2 \%$ of Pakistani children under the age of five with diarrhea receive zinc as part of their acute diarrhea treatment [3]. One of the core reasons is a lack of awareness regarding the role of oral zinc in pediatric diarrhea. Another important reason is the paucity of local data enforcing the role of zinc in alleviating acute pediatric diarrhea. The aim of this study is to establish substantial evidence regarding the role of zinc in improving the consistency and frequency of stool in acute diarrhea. 


\title{
Materials And Methods
}

This was a cross-sectional, interventional study conducted in the outpatient unit of the department of pediatrics, Civil Hospital, Jamshoro, in October 2018. One hundred children, of age 28 days till five years, presenting with acute diarrhea, were recruited after the informed consent of their parents/guardians. Children with diarrhea (>14 days), dysentery (blood in stool), and with severe dehydration requiring hospital administration were not included in the study.

\begin{abstract}
All children were prescribed a probiotic and low osmolarity ORS. A banana-yogurt diet was added for children who were taking solids. The sample was then divided into two groups. The first group ( $\mathrm{n}=50)$ was given zinc supplementation additional to the above-mentioned regime; no additional zinc

supplementation was added for the second group $(\mathrm{n}=50)$. For infants less than six months of age, $10 \mathrm{mg} / \mathrm{day}$ zinc was prescribed, and for the older age group, $20 \mathrm{mg} /$ day zinc was prescribed [4]. Age, gender, history of a previous episode of diarrhea in one month, the formula of milk (breast milk vs. formula), and the duration of diarrhea were noted for all children. On Day 1, body weight, the number of diarrhea episodes, and stool consistency were noted. All three readings were repeated on Day 3 for both the groups.
\end{abstract}

Data were entered and analyzed using IBM Statistical Package for the Social Sciences (SPSS) Statistics for Windows, version 21.0. (IBM Corp., Armonk, NY, US). Frequency and percentages were calculated for categorical data. Mean and standard deviation (SD) were calculated for continuous data. The readings of both treatment groups on Days 1 and 3 were compared via the chi-square test. A p-value of $\leqslant 0.05$ was taken as significant.

\section{Results}

There were 50 children in each group. The zinc group had more male children (58\%) and the non-zinc group had more female children (52\%). The overall mean age of the sample was $25.12 \pm 6.05$ months. The characteristics of the children, including the mean age, gender, history of acute diarrhea episodes in the last month, form of milk intake, duration of current diarrhea episode, and number of loose stools per day for both study groups, are shown in Table 1.

\begin{tabular}{|c|c|c|}
\hline Patient characteristic & Zinc group $\mathbf{n}(\%)$ & Non-zinc group $n(\%)$ \\
\hline \multicolumn{3}{|l|}{ Gender } \\
\hline Male & $29(58 \%)$ & $24(48 \%)$ \\
\hline Female & $21(42 \%)$ & $26(52 \%)$ \\
\hline Previous history of acute diarrhea within one-month & $13(26 \%)$ & $28(56 \%)$ \\
\hline \multicolumn{3}{|l|}{ Milk formula } \\
\hline Breastfeeding & $6(12 \%)$ & $7(14 \%)$ \\
\hline Formula milk (liquid) & $19(38 \%)$ & $14(28 \%)$ \\
\hline Formula milk (powdered) & $13(26 \%)$ & $18(36 \%)$ \\
\hline No milk intake & $12(24 \%)$ & $11(2 \%)$ \\
\hline Age in months (mean \pm SD) & $24.63 \pm 3.58$ & $29.38 \pm 5.74$ \\
\hline Duration of diarrhea in days (mean $\pm \mathrm{SD}$ ) & $3.05 \pm 1.24$ & $4.85 \pm 1.48$ \\
\hline Frequency of loose stools / day (mean \pm SD) & $2.57 \pm 1.11$ & $3.25 \pm 2.04$ \\
\hline
\end{tabular}

TABLE 1: Characteristics of the patient in the zinc and non-zinc groups $(n=50)$

The body weight, frequency of diarrheal episodes per day and the stool consistency for both groups were compared on Days 1 and 3. As seen in Table 2, the mean body weight and mean frequency of diarrheal episodes on Day 1 were comparable for both study groups. In the zinc group, $56 \%$ of children had stools of watery consistency. In the non-zinc group, there were $72 \%$ of children with watery diarrhea. However, on Day 3, children in the non-zinc group were noticed to have a significantly lower mean body weight as compared to the zinc group. The mean frequency of diarrheal episodes was significantly less in the zinc group than the non-zinc group. As far as the stool consistency was concerned, the zinc group showed more improvement ( $\mathrm{p}$-value $=0.01$ ). From $56 \%$ of children with watery diarrhea on Day 1 , there were only $14 \%$ of children with watery diarrhea on Day 3 in the zinc group. There were no children with firm stools in the zinc group on Day 1 and by Day 3, 54\% of children had firm stools. On the other hand, in the non-zinc group, there were $72 \%$ children with watery diarrhea on Day 1 , which only reduced to $38 \%$ on Day 3 (as compared to $14 \%$ in the zinc group). There were no children with firm stools in the non-zinc group on Day 1 and by Day 3 , 


\section{Cureus}

only $32 \%$ children had firm stools (as compared to $54 \%$ in the zinc group) (Table 2).

\begin{tabular}{|c|c|c|c|}
\hline Variable & Zinc group & Non-zinc group & $P$ value \\
\hline \multicolumn{4}{|l|}{ Day 1: } \\
\hline Mean body weight (kg) & $12.58 \pm 2.06$ & $11.89 \pm 2.65$ & 0.14 \\
\hline Mean frequency of diarrheal episodes & $6.14 \pm 0.98$ & $6.37 \pm 1.04$ & 0.25 \\
\hline \multicolumn{4}{|l|}{ Stool consistency (\%) } \\
\hline Watery & $28(56 \%)$ & $36(72 \%)$ & \multirow{3}{*}{0.09} \\
\hline Soft & $22(44 \%)$ & $14(28 \%)$ & \\
\hline Firm & -- & -- & \\
\hline \multicolumn{4}{|l|}{ Day 3: } \\
\hline Mean body weight & $11.06 \pm 1.04$ & $9.05 \pm 1.85$ & $<0.00001$ \\
\hline Mean frequency of diarrheal episodes & $2.40 \pm 0.81$ & $4.28 \pm 1.07$ & $<0.00001$ \\
\hline \multicolumn{4}{|l|}{ Stool consistency } \\
\hline Watery & $7(14 \%)$ & $19(38 \%)$ & \multirow{3}{*}{0.01} \\
\hline Soft & $16(32 \%)$ & $15(30 \%)$ & \\
\hline Firm & $27(54 \%)$ & $16(32 \%)$ & \\
\hline
\end{tabular}

TABLE 2: Comparison of the frequency and consistency of stool in the zinc and non-zinc groups on Days 1 and 3 of supplementation

\section{Discussion}

Zinc supplementation for acute diarrhea in young children was first recommended by WHO in 2004 [4]. Although Pakistan is among the first countries to include zinc in its diarrhea management, still according to Pakistan Health Survey (2012), only $2 \%$ of children were receiving zinc for diarrhea, which only increased to $8 \%$ in the 2017-2018 survey [3,8]. Furthermore, according to the National Nutrition Survey 2011, 39.2\% of Pakistani children of ages zero to five years were zinc deficient [9]. Our study concluded a significantly improved stool consistency and a reduced frequency of daily episodes of diarrhea with oral zinc supplementation.

In the past, there have been contradictory studies regarding the role of oral zinc supplementation in acute pediatric diarrhea. In a randomized open-label study from India, adding oral zinc supplementation to standard anti-diarrhea therapy resulted in less time to resolution [10]. However, a study with Polish children failed to show any significant impact of adding zinc to the anti-diarrhea regime in their pediatric population. They attribute their results to the fact that their children are not zinc-deficient [11]. This hypothesis that zinc supplementation will only benefit children with zinc deficiency is also enforced by another multinational study. Walker et al. conducted a study with infants of age 28 days till five months in Pakistan, India, and Ethiopia. The study did not find any difference in the stool frequency and rates of vomiting in the zinc and placebo groups. They also attributed their results to the fact that exclusively and predominantly breastfed infants already have a higher zinc intake than older children taking solids [12].

However, evidence supporting the role of zinc in acute pediatric diarrhea is still strong. Oral zinc supplementation significantly improved the duration of diarrhea and reduced the volume and frequency of stools within 24 hours of initiation of therapy [13]. Children being supplemented with oral zinc have better response rates, shorter duration of diarrhea, and a significantly lower recurrence rate within three months [14]. In another study, only $5 \%$ of children of the zinc group had diarrhea after 120 hours of intervention as compared to $20 \%$ of the placebo group. Furthermore, the zinc group had a lower frequency of diarrhea [15].

Diarrhea is among the most common and most prevalent pediatric illnesses, especially in middle-to-low income countries. Scientific evidence regarding the role of zinc supplementation in acute pediatric diarrhea is controversial. Large-scale, double-blind trials must be conducted to bring substantial evidence to the table. Longitudinal studies to understand the preventive role of zinc in reducing the recurrence of diarrhea in children are also the need of the hour. Pediatric infectious and public health specialists must take aggressive steps to ensure the inclusion of zinc supplementation in the anti-diarrhea regime for all Pakistani children. 


\section{Conclusions}

Oral zinc supplementation has a promising role in reducing the duration of diarrhea and improving stool consistency in children with acute diarrhea. Substantial research is still needed in this sector to reinforce the role of zinc in not only alleviating current diarrheal episodes but also in the prevention of diarrheal recurrence. Oral zinc supplementation should be made a mandatory part of the anti-diarrheal regime for Pakistani children.

\section{Additional Information \\ Disclosures}

Human subjects: Consent was obtained by all participants in this study. Liaquat University of Medical and Health Sciences, Jamshoro issued approval 18-678. I am pleased to inform you that the chairman, on behalf of the committee members of LUMHS Jamshoro, approves ethical clearance of the above-mentioned research project on this 5 th day of September 2018. The favorable opinion is given for a period of 1 year from the date of this letter and the validity may be renewed for a further period on a fresh application. Animal subjects: All authors have confirmed that this study did not involve animal subjects or tissue. Conflicts of interest: In compliance with the ICMJE uniform disclosure form, all authors declare the following: Payment/services info: All authors have declared that no financial support was received from any organization for the submitted work. Financial relationships: All authors have declared that they have no financial relationships at present or within the previous three years with any organizations that might have an interest in the submitted work. Other relationships: All authors have declared that there are no other relationships or activities that could appear to have influenced the submitted work.

\section{References}

1. Kosek M, Bern C, Guerrant RL: The global burden of diarrheal diseases as estimated from studies published between 1992 and 2000. Bull World Health Organ. 2003, 81:197-204.

2. Black RE, Morris SS, Bryce J: Where and why are 10 million children dying every year? . Lancet. 2003, 361:2226-2233.

3. Pakistan demographics and health survey. (2013). Accessed: December 22, 2018: http://nhsrc.pk/dashboards/indicatorselect.php?target=pdhs \&years=2012-13.

4. Clinical management of acute diarrhoea. (2004). Accessed: February 28, 2019: http://archives.who.int/eml/expcom/expcom14/zinc-sulfate/WHO_UNICEF-Statement_Acute_Diarrhoea.pdf.

5. WHO | Implementing the new recommendations on the clinical management of diarrhoea. Guidelines for policy makers and programme managers. (2006). Accessed: February 28, 2019: https://www.who.int/maternal_child_adolescent/documents/9241594217/en.

6. Trivedia SS, Chudasamab RK, Patel N: Effect of zinc supplementation in children with acute diarrhea: randomized double blind controlled. Gastroenterol. 2009, 2:168-174. 10.4021/gr2009.06.1298

7. Patel A, Mamtani M, Dibley MJ, Badhoniya N, Kulkarni H: Therapeutic value of zinc supplementation in acute and persistent diarrhea: a systematic review. Plos One. 2010, 5:e10386. 10.1371/journal.pone.0010386

8. Pakistan demographics and health survey. (2018). Accessed: December 7, 2018: https://dhsprogram.com/pubs/pdf/FR354/FR354.pdf.

9. Pakistan National Nutrition Survey 2011. UNICEF Pakistan . (2012). Accessed: February 28, 2019: https://www.mhinnovation.net/sites/default/files/downloads/innovation/research/Pakistan\%20National\%20Nutrition\%20Su

10. Patel HN, Shah RB, Gajjar BM: Evaluation of the role of zinc supplementation in treatment of diarrhoea in paediatric patients: a randomized open-label study. Drugs Ther Perspect. 2015, 31:34-38.

11. Patro B, Szymański H, Szajewska H: Oral zinc for the treatment of acute gastroenteritis in Polish children: a randomized, double-blind, placebo-controlled trial. J Pediatr. 2010, 157:984-988. 10.1016/j.jpeds.2010.05.049

12. Walker CL, Bhutta ZA, Bhandari N, Teka T, Shahid F, Taneja S, Black RE: Zinc supplementation for the treatment of diarrhea in infants in Pakistan, India and Ethiopia. J Pediatr Gastroenterol Nutr. 2006, 43:357363. 10.1097/01.mpg.0000232018.40907.00

13. Ahmed I, Tahir A, Malik FR: Zinc supplementation in malnourished children under 5 years with acute diarrhea. J Rawalpindi Med Coll. 2012, 16:174-176.

14. Jiang CX, Xu CD, Yang CQ: Therapeutic effects of zinc supplement as adjunctive therapy in infants and young children with rotavirus enteritis [Article in Chinese]. Zhongguo Dang Dai Er Ke Za Zhi. 2016, 18:826830.

15. Crisinel PA, Verga ME, Kouame KS, Pittet A, Rey-Bellet CG, Fontaine O, Di Paolo ER: Demonstration of the effectiveness of zinc in diarrhoea of children living in Switzerland. Eur J Pediatr. 2015, 174:1061-1067. 10.1007/s00431-015-2512-x 